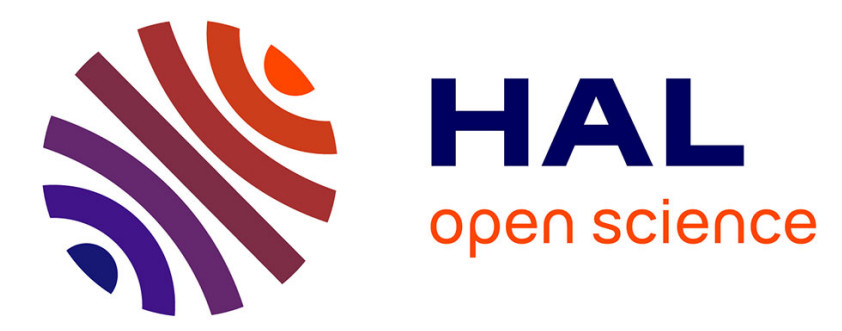

\title{
Equilibrium constants of the formation of 1,3,5-trinitro-benzene complexes and their reaction rate constants with o-Ps
}

\author{
B. Lévay
}

\section{- To cite this version:}

B. Lévay. Equilibrium constants of the formation of 1,3,5-trinitro-benzene complexes and their reaction rate constants with o-Ps. Journal de Physique IV Proceedings, 1993, 03 (C4), pp.C4-147-C4-149. 10.1051/jp4:1993420 . jpa-00251463

\section{HAL Id: jpa-00251463 https://hal.science/jpa-00251463}

Submitted on 1 Jan 1993

HAL is a multi-disciplinary open access archive for the deposit and dissemination of scientific research documents, whether they are published or not. The documents may come from teaching and research institutions in France or abroad, or from public or private research centers.
L'archive ouverte pluridisciplinaire HAL, est destinée au dépôt et à la diffusion de documents scientifiques de niveau recherche, publiés ou non, émanant des établissements d'enseignement et de recherche français ou étrangers, des laboratoires publics ou privés. 


\title{
Equilibrium constants of the formation of 1,3,5-trinitro-benzene complexes and their reaction rate constants with o-Ps
}

\author{
B. LÉVAY
}

Department of Nuclear Chemistry, Eötvös Loránd University, P.O. Box 32, 1518 Budapest 112, Hungary

\begin{abstract}
Equilibrium constants of complex formation between the strong electron acceptor 1,3,5-trinitro-benzene (TNB) and basic donors (n-butyl-amine and piperidine) were determined by positron annihilation lifetime technique. The reaction rate costants of the complexes with 0-Ps were calculated too. The results were compared with our earlier investigation on TNB in methanolic solutions of $\mathrm{NaOH} / 1 /$. All the complexes formed were so called Meisenheimer complexes $/ 2 /$. The stability of the complexes and their reactivity towards 0-Ps can be accounted for by the differences in their structure, in the size of the donor molecules and in the charge distribution on the complexes.
\end{abstract}

\section{Introduction}

Aromatic nitro-compounds are well known as strong electron acceptors easily forming donor-acceptor charge-transfer molecular complexes with bases or other nucleophilic species $/ 3 /$. The adducts with intense colours produced by the addition of bases to solutions of aromatic trinitro-compounds have come to be known as "Meisenheimer complexes" (MC). Their structure can be represented by the following general formula containing cyclohexadienate-type anion $/ 2 /$ :

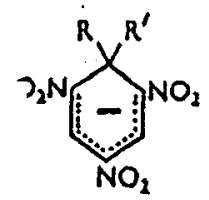

Figure 1: General formula for Meisenheimer complexes.

Structural studies has shown great differences in actual structure or charge distribution of MC-es depending on the type of donor molecules. The formation of a zwitterion for complexes with aliphatic amines and intramolecular hydrogen-bond stabilization for primary amines was postulated by Lewis and Seaborg /4/; the reaction between TNB and piperidine was interpreted by Briegleb et al. 15/ as forming weak charge-transfer complex and also a pair of ions:

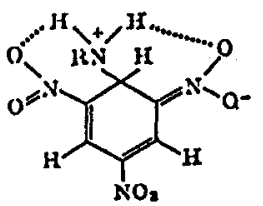

(a)<smiles>[Z1]c1cc([N+](=O)[O-])c([N+](=O)[O-])cc1[N+](=O)[O-]</smiles>

(b)

Figure 2: Structure of MC-es with $\mathrm{n}$-butyl-amine (a) and piperidine (b). 
The high electron affinity of aromatic nitro-compounds results in high reactivity towards 0-Ps. The electron affinity of a donor-acceptor complex on the other hand is generally much lower than that of the free acceptor molecule. Owing to this effect positron annihilation lifetime technique can be used to follow the process of complex formation as a function of increasing donor concentration and the equilibrium constant of complex formation can be determined $/ 6 /$.

The reactivity of aromatic acceptor molecules towards o-Ps is strongly affected by the charge distribution on the aromatic ring. Excess negative charge, e.g., can be delocalized over the conjugated system and can decreas the reactivity by filling in the low-lying vacant orbitals formed due to the effect of electron withdrawing nitro-substituents $/ 7 /$.

The aim of the present work was to continue our studies on MC-es formed from TNB with different basic donor molecules and to get information about the stability and structure of the complexes.

\section{Experimental}

Positron lifetime spectra were recorded by a fast-fast coincidence spectrometer with a time resolution of $280 \mathrm{ps}$. The lifetime measurements were carried out at $20^{\circ} \mathrm{C}$ under atmospheric pressure of air.

The concentration of TNB in methanol was kept constant at $C_{\text {TNB }}=0.025 \mathrm{M}$ and $0.020 \mathrm{M}$ in case of $\mathbf{n}$-butyl-amine and piperidine respectively and the concentration of the donors varied in the $C_{D}=0-3.5 \mathrm{M}$ and $0-3.0 \mathrm{M}$ range respectively. The equilibrium constants of the complex formation $(\mathrm{K})$ were calculated by using the formula derived earlier $/ 1$ :

$$
\left(\lambda_{0}-\lambda_{c}\right) / C_{D}=K \lambda_{C}-K \lambda_{\infty}
$$

where the $0-P S$ annihilation rate, $\lambda_{0}$ was measured in a TNB solution at $C_{T N B}$ and $C_{D}=0 ; \lambda_{c}$ was measured at $C_{T N B}$ as a function of $C_{D} \cdot \lambda_{\infty}$ stands for the extrapolated value of $\lambda_{C}$ to $C_{D}=\infty$, i.e., when the concentration of the $\mathrm{MC}\left(\mathrm{C}_{\mathrm{MC}}\right)$ is assumed to be equal to $\mathrm{C}_{\mathrm{TNB}}$.

A plot of the left hand term of equation (1) against $\lambda_{c}$ has been found to be linear and from the gradient of the line $K$, and from its intercept with the $X$ axis $\lambda_{\infty}$ have been evaluated. The reaction rate constants (k) of the MC-es towards o-Ps were calculated from $\lambda_{\infty}$ according to the well known equation (2):

$$
\lambda_{\infty}=\lambda(0)+\mathrm{k} \cdot \mathrm{C}_{\mathrm{MC}}
$$

where $\lambda(0)$ stands for the o-Ps annihilation rate in the pure solvent and $\mathrm{C}_{\mathrm{MC}}=\mathrm{C}_{\mathrm{TNB}}$.

\section{Results and discussion}

The results are shown in Table 1, for comparison together with that measured earlier in methanolic solutions of $\mathrm{NaOH} / 1 \%$. 
Table 1: Equilibrium contants of MC-es formed from TNB with different basic donors and the reaction rate contants of MC-es towards o-Ps in methanol.

\begin{tabular}{|lcc|}
\hline Donor & $\mathbf{K}$ & $\mathbf{k} .10^{-10}$ \\
& {$\left[\mathrm{M}^{-1}\right]$} & {$\left[\mathrm{M}^{-1} \mathrm{~S}^{-1}\right]$} \\
- & - & $(3.8 \pm 0.2)$ \\
$\mathrm{NaOCH} 3$ & $11.4 \pm 0.5$ & $(0.6 \pm 0.1)$ \\
n-butyl-amine & $1.8 \pm 0.1$ & $(0.8 \pm 0.1)$ \\
piperidine & $0.50 \pm 0.05$ & $\leq 0.01$ \\
\hline
\end{tabular}

The MC with methoxide adduct is about one order of magnitude more stable then those formed with amines. This fact can reasonably well be accounted for by steric effects. The stability seems to decrease with increasing steric hindrance caused by the donor molecules. On the other hand the higher stability of the n-butyl-amine complex as compared to that of the piperidine can be explained by the stabilization effect of the intramolecular hydrogen-bond formation.

The reactivity of the MC-es towards o-Ps are significantly lower than that of the free electron acceptor TNB. In general terms this can be interpreted by the filling in of the low-lying vacant orbitals of TNB by charge transfer from the electron donors.

The somewhat higher reaction rate constant for the $\mathrm{n}$-butyl-amine adduct as compared to that of the methoxide one can be accounted for by the differences in the charge distribution on the aromatic ring. The result seems to be in agreement with the assumption that the n-butyl-amine adduct is a zwitterion with an overall neutral charge while the adduct with methoxide has one unit excess negative charge delocalized on the benzene ring.

The extremly low reactivity of the piperidine adduct, which has also one unit delocalized excess negative charge on its conjugated system, might be the result of the presence of the positive counter ion which can partly hinder the interaction between o-Ps and the complex.

\section{Summary}

Positron annihilation technique was used for determining stability of Meisenheimer complexes formed from 1,3,5-trinitro-benzene with different basic donors. The differences in stability of the adducts and their reactivity towards o-Ps were accounted for by steric hindrances and hydrogen-bond stabilization caused by the donor molecules and by differences in the charge distribution on the complexes.

\section{References}

/1/ LÉVAY, B., Materials Sci. Forum, 105-110 (1992) 1629

/2/ CRAMPTON, M.R., Advances in Physical Organic Chemistry (Gold, V., Ed.), Academic Press, London Vol. 7 (1969) 211.

13/ FORSTER, R., Organic Charge Transfer Complexes, Academic Press, New York (1969).

14/ LEWIS, G.N., SEABORG, G.T., J. Am. Chem. Soc. 62 (1940) 2122.

15/ BRIEGLEB, G., LIPTAY, W., CANTNER, M., Z. Physik. Chem. (Frankfurt) 26 (1960) 55.

/6/ LÉVAY, B., HAUTOJÄRVI, P., J. Phys. Chem. 76 (1972) 1951.

/7/ LÉVAY, L., LÉVAY, B., VERTES, A., Chem. Phys. 124 (1988) 155. 